\title{
Formation of Sclerotia and Aflatoxins in Developing Cotton Bolls Infected by the S Strain of Aspergillus flavus and Potential for Biocontrol with an Atoxigenic Strain
}

\author{
R. K. Garber and P. J. Cotty
}

Southern Regional Research Center, Agricultural Research Service, U.S. Department of Agriculture, P.O. Box 19687, New Orleans, LA 70179. Accepted for publication 12 May 1997.

\section{ABSTRACT}

Garber, R. K., and Cotty, P. J. 1997. Formation of sclerotia and aflatoxins in developing cotton bolls infected by the S strain of Aspergillus flavus and potential for biocontrol with an atoxigenic strain. Phytopathology 87:940-945.

Aspergillus flavus can be divided into the $\mathrm{S}$ and $\mathrm{L}$ strains on the basis of sclerotial morphology. On average, $\mathrm{S}$ strain isolates produce greater quantities of aflatoxins than do L strain isolates. Sclerotia of the $\mathrm{S}$ strain were observed in commercial seed cotton from western Arizona. Greenhouse tests were performed to better define sclerotial formation in developing bolls. Eight $\mathrm{S}$ strain isolates were inoculated into developing bolls via simulated pink bollworm exit holes. All eight isolates formed sclerotia on locule surfaces, and seven of eight isolates produced sclerotia within developing seed. Boll age at inoculation influences formation of sclerotia. More sclerotia formed within bolls that were less than 31 days old at inoculation than in bolls older than 30 days at inoculation. Frequent formation of sclerotia during boll infection may both favor $\mathrm{S}$ strain success within cotton fields and increase toxicity of A. flavus-infected cottonseed. Atoxigenic A. flavus L strain isolate AF36 reduced formation of both sclerotia and aflatoxin when coinoculated with S strain isolates. AF36 formed no sclerotia in developing bolls and was more effective at preventing $\mathrm{S}$ strain isolates than $\mathrm{L}$ strain isolates from contaminating developing cottonseed with aflatoxins. The use of atoxigenic $\mathrm{L}$ strain isolates to prevent contamination through competitive exclusion may be particularly effective where $\mathrm{S}$ strain isolates are common. In addition to aflatoxin reduction, competitive exclusion of $\mathrm{S}$ strain isolates by $\mathrm{L}$ strain isolates may result in reduced overwintering by $\mathrm{S}$ strain isolates and lower toxicity resulting from sclerotial metabolites.

Additional keywords: biocompetition, mycotoxins.
Aflatoxins are a group of toxic, carcinogenic fungal metabolites produced by certain isolates of Aspergillus flavus Link:Fr., A. parasiticus Speare, and A. nomius Kurtzman et al. (23). Regulatory limitations on the quantity of aflatoxins permitted in foods and feeds exist throughout most of the world (26). The most toxic and highly regulated aflatoxin is $\mathrm{B}_{1}$, which is produced by all three aflatoxin-producing species $(20,26)$. Aflatoxin contamination has long been a concern for the United States cottonseed industry (20), because aflatoxins in contaminated seed can be readily transferred to milk of dairy cows in slightly modified form (19, 22). Cottonseed is a preferred feed for dairy cows, and United States regulations prohibit aflatoxin concentrations over $0.5 \mu \mathrm{g} / \mathrm{kg}$ in milk (15). A. flavus is the primary causal agent of aflatoxin contamination of cottonseed. In the United States, aflatoxin contamination of cottonseed is most severe in western Arizona, where contamination is frequently associated with A. flavus infection of developing bolls through pink bollworm exit holes (12). Greenhouse techniques to study A. flavus infection through simulated pink bollworm exit holes have been developed (5).

On the basis of physiological, morphological, and genetic criteria, A. flavus can be divided into two strains, S and L $(2,4)$. Isolates of the $S$ strain produce numerous small sclerotia $(<400 \mu \mathrm{m}$ in diameter) and fewer conidia than $\mathrm{L}$ strain isolates. Strain $\mathrm{S}$ isolates produce, on average, more aflatoxin than $\mathrm{L}$ strain isolates both in culture and within developing cottonseed (4). Many L strain isolates produce little or no aflatoxins $(4,13)$. In Arizona, where afla-

Corresponding author: P. J. Cotty; E-mail address: pjcotty@nola.srrc.usda.gov

Publication no. P-1997-0609-01R

This article is in the public domain and not copyrightable. It may be freely reprinted with customary crediting of the source. The American Phytopathological Society, 1997. toxin contamination of cottonseed is severe, the $\mathrm{S}$ strain is often dominant $(9,18)$. Although several characteristics of the $S$ strain suggest soil adaptation (11), little data on the divergent ecologies of the $\mathrm{S}$ and $\mathrm{L}$ strains are available. Multiple A. flavus strains are known to frequently infect individual locules and seed (1), but interactions between $\mathrm{S}$ strain and $\mathrm{L}$ strain isolates during seed infection have not been described.

High concentrations of aflatoxins may occur in both conidia and sclerotia of A. flavus (28), and certain toxicities associated with $A$. flavus contamination have been attributed to combined activities of aflatoxins and other metabolites present in sclerotia $(14,28,29)$. Over the past 7 years, we have occasionally observed sclerotia of the S strain of A. flavus on surfaces of "tight locks" (cotton locules that do not open fully) in commercial cotton in western Arizona. The $\mathrm{S}$ strain of A. flavus is widely distributed among cotton-producing regions (9). Yet, formation of sclerotia by A. flavus within developing crops has been infrequently described $(16,24,30)$, and formation on cotton boll locule surfaces has not been described.

Certain $\mathrm{L}$ strain isolates effectively reduce aflatoxin $\mathrm{B}_{1}$ levels in cottonseed when coinoculated with aflatoxin-producing isolates (6). These atoxigenic strains reduce contamination by competitively excluding aflatoxin-producing isolates during crop infection (10). Atoxigenic strains are being developed as biological control agents directed at preventing aflatoxin contamination $(7,8)$. However, the efficacy of atoxigenic L strain isolates in limiting aflatoxin contamination of cottonseed caused by S strain isolates has not been detailed. Furthermore, it is unknown if atoxigenic L strain isolates can interfere with sclerotial formation by $\mathrm{S}$ strain isolates and, in so doing, further reduce seed toxicity by also lowering the incidence of toxins of sclerotial origin.

Boll age at inoculation influences aflatoxin formation in developing cottonseed (5) and may similarly affect the ability of $A$. flavus $\mathrm{S}$ strain isolates to colonize cotton locules and produce scle- 
rotia within colonized plant tissue. Such influences may dictate the relative importance of S strain sclerotia to the epidemiology of aflatoxin contamination in the field.

The current study describes, for the first time, sclerotial formation by $\mathrm{S}$ strain isolates on locule surfaces and within developing cottonseed. Efficacy of an atoxigenic L strain isolate in limiting both aflatoxin and sclerotial formation by $\mathrm{S}$ strain isolates during coinfection of cotton bolls is also described.

\section{MATERIALS AND METHODS}

Media and cultures. A. flavus $\mathrm{S}$ strain isolates from agricultural soils collected in Arizona (AF12, AF65, D2-9, MR3-15, MR5-23, PM3, YV1-1, and YV5-12), Alabama (AL3-39), Louisiana (LA2-5), and Mississippi (STV4-28) were used. L strain isolates (D2-18, PM11, WHT-3, and YV1) used in the aflatoxin production study were isolated from agricultural soils collected in Arizona. Isolate AF36 was isolated from cottonseed collected from the Yuma Valley of Arizona (4). Cultures were maintained in the dark at $31^{\circ} \mathrm{C}$ on a medium containing $5 \% \mathrm{~V}-8$ juice and $2 \%$ agar (4). For longterm storage, plugs ( $3 \mathrm{~mm}$ in diameter) of sporulating cultures were placed in 12-ml vials containing $5 \mathrm{ml}$ of distilled water and refrigerated at $8^{\circ} \mathrm{C}(5)$. Inoculum was prepared by suspending conidia from 7- to 10-day-old cultures in distilled deionized water.

Infection of cotton bolls and developing cottonseed. Plants of Gossypium hirsutum L. (Deltapine 90) were grown in a greenhouse in 3-liter pots containing a 1:1:1 mixture of Pro-mix (Premier Brands, Inc., New Rochelle, NY), coarse sand, and clay loam topsoil. Temperature ranged from 28 to $36^{\circ} \mathrm{C}$, and supplemental lighting (400-W General Electric Lucalux bulbs; GTE Corp., Stamford, CT) was applied for 3 h (6 p.m. to 9 p.m.) daily. After 21 days, each plant was fertilized weekly with approximately $500 \mathrm{ml}$ of nutrient solution containing $4 \mathrm{ml} /$ liter of Peter's fertilizer (20-20-20, N-P-K; W. R. Grace \& Co., Allentown, PA). One application of Peter's Soluble Trace Element Mix (W. R. Grace \& Co.) was administered immediately after planting. Plants were sacrificed 45 days after planting.

Developing cotton bolls were inoculated through simulated exit holes of the pink bollworm as previously described (5). Flowers were tagged and dated at opening. In all experiments, bolls were wounded ( 1 to $2 \mathrm{~mm}$ deep) in a single locule with a cork borer ( 3 $\mathrm{mm}$ in diameter) and inoculated by placing a $10-\mu \mathrm{l}$ aliquot of conidial suspension (about 2,000 conidia) in the wound. For coinoculation experiments, conidial suspensions (10 $\mu \mathrm{l}, \sim 2,000$ conidia) of each isolate were applied to the same wound.

To assess influences of $A$. flavus AF36 on sclerotial formation by $\mathrm{S}$ strain isolates, bolls 25 to 30 days old were inoculated with either an $\mathrm{S}$ strain isolate alone or both an S strain isolate and AF36, simultaneously. In each test, four $\mathrm{S}$ strain isolates were tested. Treatments were replicated four times and arranged in randomized complete blocks. Replicates consisted of individual plants bearing one or two bolls.

Two separate greenhouse experiments were conducted to determine if the in vivo influence of A. flavus AF36 on aflatoxin production by $\mathrm{S}$ strain isolates was similar to the influence of AF36 on aflatoxin production by $\mathrm{L}$ strain isolates $(6,10)$. In each experiment, the influence of AF36 on aflatoxin contamination of developing cotton bolls by two $\mathrm{S}$ strain and two $\mathrm{L}$ strain isolates was evaluated. Comparisons were made between bolls (27 to 32 days old) inoculated with only an aflatoxin-producing isolate and bolls inoculated with AF36 immediately after the aflatoxin-producing isolate. Treatments were replicated four to five times, and plants were arranged on greenhouse benches in randomized complete blocks (one plant per replicate per treatment).

To assess the influence of boll age at inoculation on sclerotial formation by $\mathrm{S}$ strain isolates on cotton locule surfaces and in developing cottonseed, cotton bolls at various stages of development (16 to 34 days after flowering) were inoculated. In each of two tests, all bolls (two to five per plant) on four plants were inocu- lated with one of four S strain isolates. Values from all plants inoculated with the same isolate were averaged to form a replicate value. Each of the two tests had four replicates (four isolates), and different isolates were used in each test. In a third experiment, bolls of varying age (16 to 34 days old) on 20 plants were inoculated with a single $S$ strain isolate (LA2-5).

Measurement of sclerotia and aflatoxin $B_{1}$ in boll tissues. Bolls were harvested in all experiments 17 days after inoculation and dried in a forced-air oven at $60^{\circ} \mathrm{C}$ for $72 \mathrm{~h}$. After drying, wound-inoculated locules were separated from adjacent uninoculated locules and stored at room temperature $\left(21\right.$ to $\left.28^{\circ} \mathrm{C}\right)$ in sealed $20-\mathrm{ml}$ plastic vials until analyzed. After weighing, woundinoculated locules were evaluated for the presence of sclerotia on locule surfaces using the following rating system: $0=$ no sclerotia; $1=1$ to 25 sclerotia; $2=26$ to 50 sclerotia; $3=51$ to 100 sclerotia; $4=101$ to 250 sclerotia; $5=251$ to 500 sclerotia; $6=501$ to 1,000 sclerotia; and $7=>1,000$ sclerotia present. Seeds were then separated from lint by hand and halved longitudinally with a razor blade. The percentage of seed per locule with sclerotia, conidiophores, or both was determined with a dissecting microscope (30× magnification). The number of sclerotia per seed was also recorded.

Aflatoxin $\mathrm{B}_{1}$ concentrations in inoculated locules were determined as previously described (6). Briefly, intact locules were pulverized and extracted with an $85 \%$ aqueous acetone solution. Extracts were purified, partitioned against methylene chloride, and concentrated. Concentrates and aflatoxin standards were separated on thin-layer chromatography plates (silica gel 60, $250 \mu \mathrm{m}$ ) by development with diethyl ether-methanol-water (96:3:1). Extracts were either concentrated or diluted to permit accurate densitometry, and aflatoxin $\mathrm{B}_{1}$ was quantified with a scanning densitometer (model cs-390; Shimadzu Scientific Instruments, Inc., Tokyo) (21).

Statistical analyses. Analyses were performed with the Statistical Analysis System (SAS Institute, Inc., Cary, NC) and Statistica (StatSoft, Inc., Tulsa, OK). For comparisons among isolates and between bolls inoculated by an S strain isolate alone and those coinoculated with both an $\mathrm{S}$ strain isolate and an $\mathrm{L}$ strain isolate, plants (one to two bolls each with a single inoculated locule per boll) served as replicates. Prior to statistical analyses, all percent values were transformed to the arcsin of the square root of the percent as recommended by Sokal and Rohlf (25). Values for number of sclerotia per seed and aflatoxin $\mathrm{B}_{1}$ concentration were square root-transformed and log-transformed, respectively, in order to homogenize the variance among treatments. Analysis of variance was performed on all multiple comparisons prior to mean separation tests. When significant differences were detected, mean values were separated using Fisher's least significant difference test. Pearson product-moment correlations were calculated for the influence of boll age at inoculation on sclerotial formation within seed and on locule surfaces. Values for individual inoculated locules were used for these calculations. For comparisons between bolls greater than 30 days old and bolls less than 31 days old at inoculation, data from tests 1 and 2 were subjected to analysis of variance, in which all locules inoculated with a particular isolate constituted a replicate. For test 3, individual locules inoculated with LA2-5 served as replicates in the analysis of variance.

\section{RESULTS}

Formation of sclerotia in developing locules. All S strain isolates produced sclerotia on locule surfaces when inoculated into 25- to 30-day-old bolls via simulated pink bollworm exit holes (Fig. 1, Table 1). Sclerotia formed in clusters on inoculated locule surfaces, closely resembling those observed on tight locules collected from the commercial crop in western Arizona (Fig. 1). The morphologies and sizes of sclerotia were typical for the S strain. Most isolates produced relatively high numbers of sclerotia on locule surfaces, averaging over 100 sclerotia per locule. One isolate, STV4-28, 
produced significantly $(P=0.05)$ fewer sclerotia, averaging less than 26 per locule. AF36 produced no sclerotia on either locule surfaces or in developing seed in either test. However, cottonseed formed within locules inoculated with AF36 frequently contained conidia between the seed coat and cotyledon (Table 1).

Seven of eight $S$ strain isolates produced sclerotia within developing seed (Figs. 2 and 3, Table 2). Sclerotia initially formed between the seed coat and the developing cotyledons (Fig. 2) and, in certain seed, progressed to replace most of the cotyledons (Fig. 3).

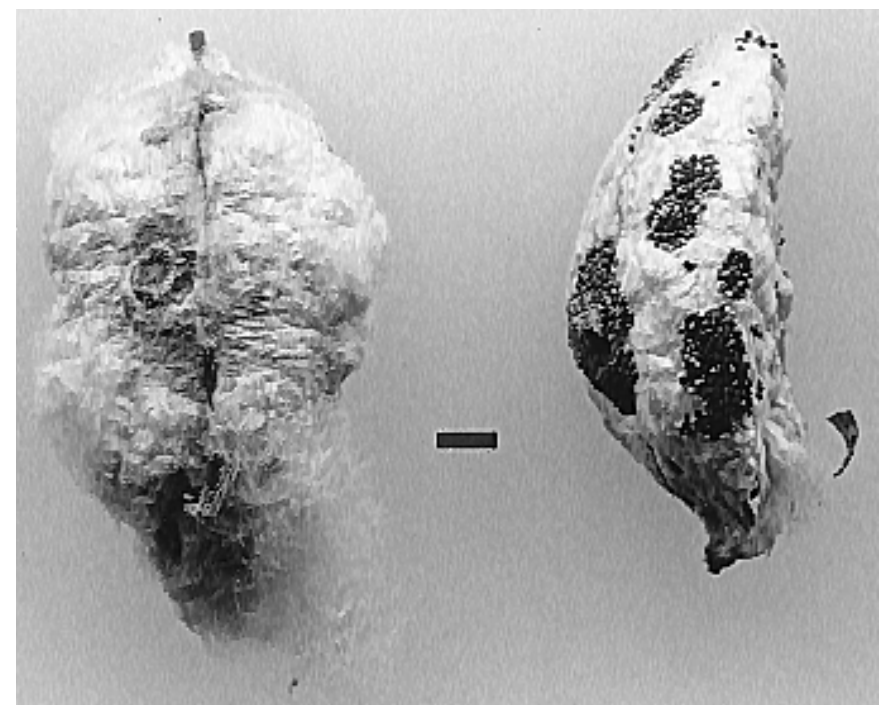

Fig. 1. Locules inoculated with Aspergillus flavus S strain isolate LA2-5 alone (right) and in combination with A. flavus isolate AF36 (left). Sclerotia only formed on locules inoculated with an S strain isolate. Far fewer sclerotia formed on locules inoculated with both AF36 and an S strain isolate. Bar represents 3 $\mathrm{mm}$.

TABLE 1. Influence of coinoculation with Aspergillus flavus AF36 on dry weights of cotton locules inoculated with $\mathrm{S}$ strain isolates and on formation of both conidia within developing seed and sclerotia on locule surfaces

\begin{tabular}{lccc}
\hline Isolate & $\begin{array}{c}\text { Locule dry weight } \\
(\mathrm{mg})\end{array}$ & $\begin{array}{c}\text { Sclerotial } \\
\text { rating }\end{array}$ & $\begin{array}{c}\text { Seed with conidia } \\
(\%)\end{array}$ \\
\hline Test 1 & & & \\
AF-36 & $671.30 \mathrm{~b}$ & $0.0 \mathrm{c}^{\mathrm{z}}$ & $57 \mathrm{a}^{\mathrm{z}}$ \\
AL3-39 (strain S) & $602.13 \mathrm{~b}$ & $4.6 \mathrm{a}$ & $0 \mathrm{~b}$ \\
AL3-39+ AF36 & $739.25 \mathrm{~b}$ & $1.6 \mathrm{~b}$ & $56 \mathrm{a}$ \\
MR3-15 (strain S) & $719.25 \mathrm{~b}$ & $5.9 \mathrm{a}$ & $0 \mathrm{~b}$ \\
MR3-15 + AF36 & $790.25 \mathrm{~b}$ & $0.4 \mathrm{bc}$ & $66 \mathrm{a}$ \\
LA 2-5 (strain S) & $632.50 \mathrm{~b}$ & $5.5 \mathrm{a}$ & $0 \mathrm{~b}$ \\
LA 2-5 + AF36 & $589.25 \mathrm{~b}$ & $1.5 \mathrm{~b}$ & $64 \mathrm{a}$ \\
YV5-12 (strain S) & $783.25 \mathrm{~b}$ & $5.8 \mathrm{a}$ & $0 \mathrm{~b}$ \\
YV5-12 + AF36 & $699.25 \mathrm{~b}$ & $0.0 \mathrm{c}$ & $75 \mathrm{a}$ \\
Not inoculated & $1,179.13 \mathrm{a}$ & $0.0 \mathrm{c}$ & ND \\
Test 2 & & & \\
AF36 & $709.10 \mathrm{bc}$ & $0.0 \mathrm{~d}$ & $54 \mathrm{a}$ \\
MR5-23 (strain S) & $733.13 \mathrm{bc}$ & $3.8 \mathrm{a}$ & $0 \mathrm{~b}$ \\
MR5-23 + AF36 & $775.33 \mathrm{bc}$ & $2.0 \mathrm{~b}$ & $54 \mathrm{a}$ \\
PM 3 (strain S) & $593.56 \mathrm{c}$ & $3.4 \mathrm{a}$ & $0 \mathrm{~b}$ \\
PM 3 AF36 & $575.33 \mathrm{c}$ & $1.5 \mathrm{bc}$ & $46 \mathrm{a}$ \\
STV4-28 (strain S) & $747.75 \mathrm{bc}$ & $1.5 \mathrm{bc}$ & $0 \mathrm{~b}$ \\
STV4-28 + AF36 & $645.08 \mathrm{bc}$ & $0.4 \mathrm{~cd}$ & $30 \mathrm{a}$ \\
YV1-1 (strain S) & $580.58 \mathrm{c}$ & $4.3 \mathrm{a}$ & $0 \mathrm{~b}$ \\
YV1-1 + AF36 & $810.58 \mathrm{~b}$ & $0.5 \mathrm{~cd}$ & $51 \mathrm{a}$ \\
Not inoculated & $1,077.38 \mathrm{a}$ & $0.0 \mathrm{~d}$ & ND \\
\hline
\end{tabular}

${ }^{y}$ The number of sclerotia present on the surface of inoculated locules was rated as follows: $0=$ no sclerotia; $1=1$ to 25 sclerotia; $2=26$ to 50 sclerotia; $3=51$ to 100 sclerotia; $4=101$ to 250 sclerotia; $5=251$ to 500 sclerotia; $6=501$ to 1,000 sclerotia; and $7=>1,000$ sclerotia.

${ }^{\mathrm{z}}$ Values are means of four replicates (locules). Means were compared using Fisher's protected least significant difference test, and values within the same column followed by a common letter are not significantly different $(P$ $=0.05)$. $\mathrm{ND}=$ not detected.
In both tests and for all isolates, sclerotia were not produced in most seed from inoculated locules (Table 2). However, in certain seed, large numbers of sclerotia formed, resulting in averages of over 25 sclerotia per seed for five of the eight $S$ strain isolates (Fig. 3, Table 2). Isolates differed in ability to produce sclerotia within developing seed (Table 2). Isolate LA2-5 formed sclerotia within the highest percentage of seed; isolate STV4-28 formed no sclerotia within seed.

In each of the three tests in which bolls of varying age were inoculated with $\mathrm{S}$ strain isolates, the number of sclerotia formed on locule surfaces decreased with increasing boll age (Pearson product-moment correlations: $r=-0.45$ to $-0.73, P<0.001$ ) (Fig. 4). Although the percentage of seed containing $\mathrm{S}$ strain sclerotia also apparently decreased with boll age at inoculation, this trend was significant for only test 3 (Pearson product-moment correlations: $r=-0.25,-0.39$, and $-0.44 ; P=0.20,0.07,<0.001)$. These trends were primarily a result of reduced production of sclerotia in bolls greater than 30 days old at inoculation (Table 3 ).

Effect of coinoculation with AF36. Coinoculation with AF36 significantly reduced the number of sclerotia formed on surfaces of locules inoculated with S strain isolates (Table 1). Similarly, coinoculation with AF36 frequently reduced both the percentage of

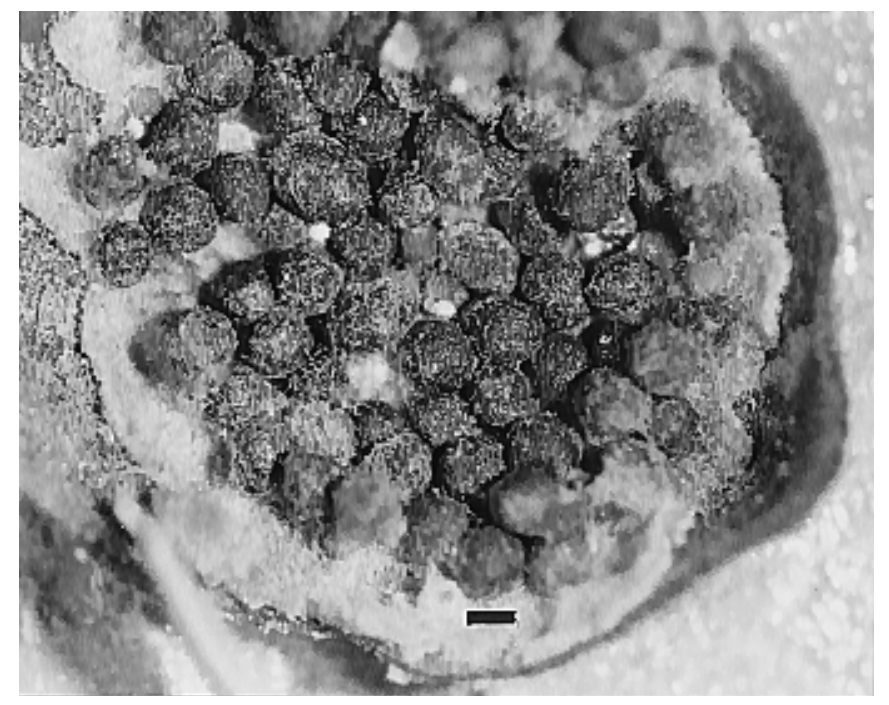

Fig. 2. Formation of sclerotia between a cotyledon and the seed coat. This in the location where sclerotia were most frequently observed. Bar represents $100 \mu \mathrm{m}$.

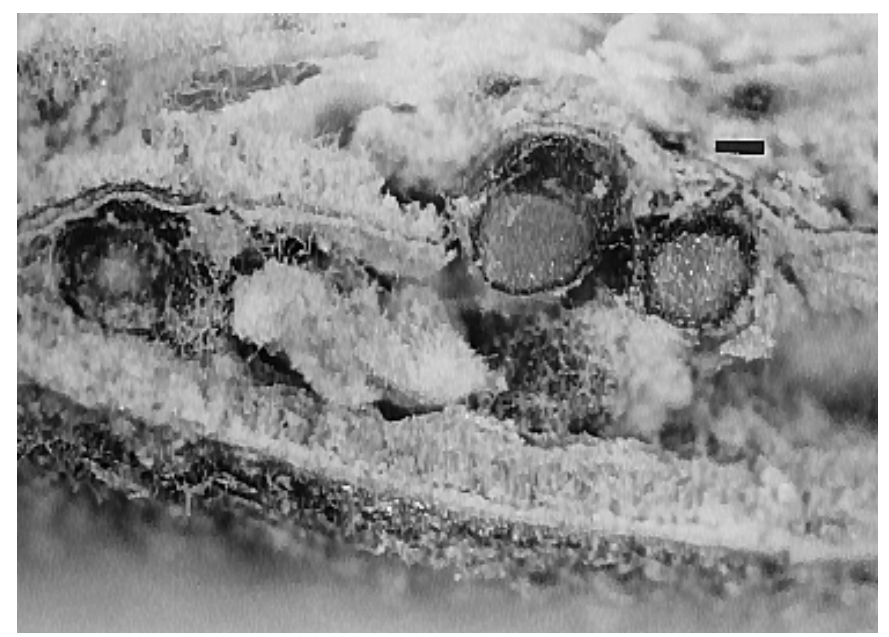

Fig. 3. Cross section of a cottonseed from a locule inoculated with Aspergillus flavus S strain isolate LA2-5. Most of the endosperm is replaced by sclerotia. Bar represents $100 \mu \mathrm{m}$. 
seed containing sclerotia and the number of sclerotia per seed (Table 2). Seed produced in locules coinoculated with AF36 consistently contained Aspergillus conidiophores between the cotyledons and seed coat; whereas seed produced both within uninoculated control locules and locules inoculated with an S strain isolate alone contained no conidiophores (Table 1).

Isolate AF36 reduced $(P<0.01)$ aflatoxin $\mathrm{B}_{1}$ production by the four tested $\mathrm{S}$ strain isolates over $99.9 \%$ when coinoculated into developing cotton bolls (Table 4). However, AF36 only reduced aflatoxin production by two of the four L strain isolates tested. For those two isolates, reductions of 88 to $96 \%$ were achieved.

In both greenhouse tests, inoculation of developing cotton locules resulted in reductions in locule dry weight compared with noninoculated controls (Table 1). The magnitude of dry weight loss in bolls inoculated with AF36 did not exceed losses in bolls inoculated by any of the $\mathrm{S}$ strain isolates. Coinoculation of bolls

TABLE 2. Influence of coinoculation with Aspergillus flavus AF36 on sclerotial formation by A. flavus $\mathrm{S}$ strain isolates within developing cotton seed

\begin{tabular}{|c|c|c|c|c|c|}
\hline \multirow[b]{2}{*}{ Isolate } & \multirow{2}{*}{$\begin{array}{c}\text { Seed } \\
\text { evaluated } \\
(\#)\end{array}$} & \multicolumn{2}{|c|}{ Seed with sclerotia (\%) } & \multicolumn{2}{|c|}{ Sclerotia per seed (\#) } \\
\hline & & Inoculated & $\overline{\text { Coinoculated }}$ & Inoculated & $\overline{\text { Coinoculated }}$ \\
\hline \multicolumn{6}{|l|}{ Test 1} \\
\hline AL3-39 & $39,36^{y}$ & $29 \mathrm{ab}^{\mathrm{z}}$ & $3 \mathrm{c}$ & $34.8 \mathrm{ab}$ & $1.0 \mathrm{c}$ \\
\hline MR3-15 & 46,38 & $13 \mathrm{bc}$ & $0 \mathrm{c}$ & $6.3 \mathrm{bc}$ & $0.0 \mathrm{c}$ \\
\hline LA2-5 & 34,49 & $45 \mathrm{a}$ & $2 \mathrm{c}$ & $78.6 \mathrm{a}$ & $0.1 \mathrm{c}$ \\
\hline YV5-12 & 29,34 & $26 \mathrm{~b}$ & $0 \mathrm{c}$ & $33.7 \mathrm{ab}$ & $0.0 \mathrm{c}$ \\
\hline \multicolumn{6}{|l|}{ Test 2} \\
\hline MR5-23 & 56,67 & $5 \mathrm{ab}$ & $2 \mathrm{~b}$ & $25.0 \mathrm{ab}$ & $20.8 \mathrm{ab}$ \\
\hline PM3 & 55,53 & $7 \mathrm{ab}$ & $2 \mathrm{~b}$ & $32.3 \mathrm{a}$ & $1.0 \mathrm{~b}$ \\
\hline STV4-28 & 56,62 & $0 \mathrm{~b}$ & $0 \mathrm{~b}$ & $0.0 \mathrm{~b}$ & $0.0 \mathrm{~b}$ \\
\hline YV1-1 & 54,56 & $26 \mathrm{a}$ & $0 \mathrm{~b}$ & $6.3 \mathrm{ab}$ & $0.0 \mathrm{~b}$ \\
\hline
\end{tabular}

y The first value is the number of seed evaluated that were inoculated with the S strain isolate alone (inoculated) and the second value is the number of seeds evaluated that were coinoculated with strain AF36 (coinoculated).

${ }^{\mathrm{z}}$ For each parameter, values within a test followed by a common letter are not significantly different $(P=0.05)$ by Fisher's protected least significant difference test. Letters apply to both comparisons within columns and comparisons between columns.

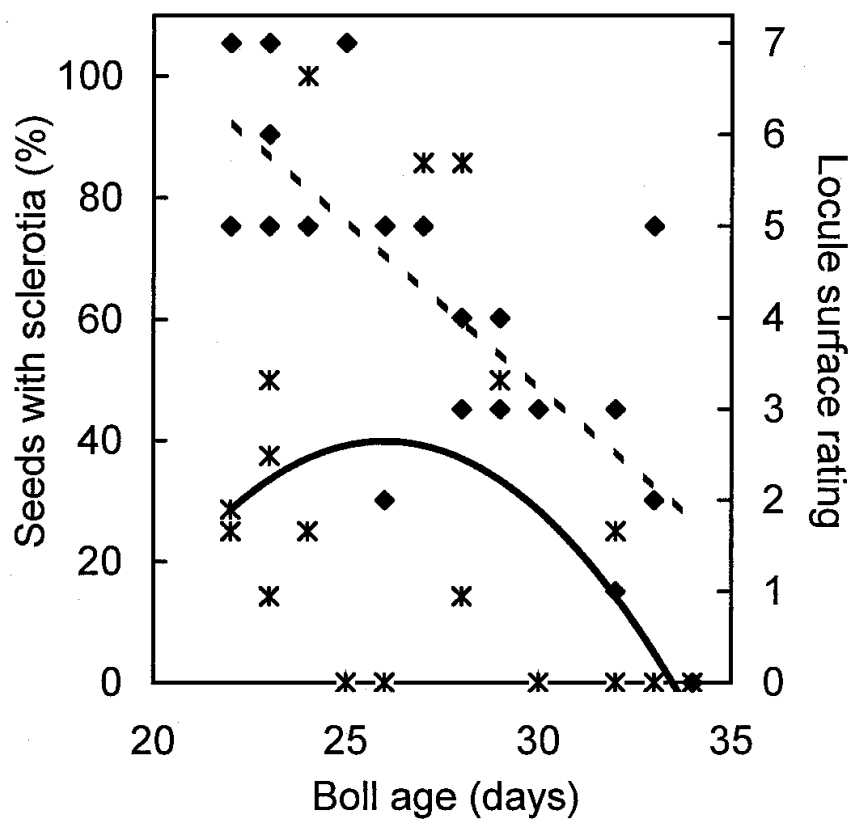

Fig. 4. Relationship between boll age at inoculation and formation of sclerotia by S strain isolate LA2-5 (test 3, Table 4) on locule surfaces (diamonds with dotted) and within developing seed (crosses with solid line). Data points represent values for single locules. with AF36 and any of the S strain isolates did not result in further locule weight loss as compared with inoculation with the $S$ strain isolate alone. However, coinoculation of AF36 with isolate YV1-1 resulted in significantly smaller biomass reductions than when YV1-1 was inoculated alone (Table 1).

\section{DISCUSSION}

All of the S strain isolates tested colonized cotton bolls and formed sclerotia on cotton locule surfaces. Seven of eight $S$ strain isolates were also able to form sclerotia within developing seed. In cotton boll inoculation experiments, formation of sclerotia by $\mathrm{L}$ strain isolates on locules and in seed has not been observed in either the current or previous $(4,5)$ studies. Similarly, S strain isolates produced sclerotia on pistachio litter, but $\mathrm{L}$ strain isolates did not (13). Although sclerotia of A. flavus (L strain) have been reported on wound-inoculated corn (30), formation of sclerotia on crops by A. flavus is not frequently observed (24). This may stem from both failure to recognize $S$ strain sclerotia and dominance of L strain isolates during boll infection. Waked and Nouman (27) found most aflatoxin within seed that also contained sclerotia when cottonseed collected in Arizona were deliberately stored in the laboratory under conditions favorable to A. flavus seed decay. Based on the high toxigenicity of the $\mathrm{S}$ strain, its frequent occurrence in Arizona $(4,9,18)$, and the results on sclerotial formation from the

TABLE 3. Sclerotial formation on locule surfaces and within seed of cotton bolls inoculated with $\mathrm{S}$ strain isolates of Aspergillus flavus either prior to or after 31 days of age

\begin{tabular}{|c|c|c|c|c|c|c|}
\hline \multirow[b]{2}{*}{ Test $^{\mathrm{y}}$} & \multicolumn{3}{|c|}{ Sclerotial rating on locule surface ${ }^{\mathrm{w}}$} & \multicolumn{3}{|c|}{ Percentage of seed containing sclerotia } \\
\hline & $\begin{array}{c}<31 \text { days } \\
\text { old }\end{array}$ & $\begin{array}{c}>30 \text { days } \\
\text { old }\end{array}$ & $P^{z}$ & $\begin{array}{c}<31 \text { days } \\
\text { old }\end{array}$ & $\begin{array}{c}>30 \text { days } \\
\text { old }\end{array}$ & $P$ \\
\hline 1 & 5.77 & 2.82 & $<0.01$ & 38.4 & 11.4 & 0.13 \\
\hline 2 & 3.34 & 0.92 & $<0.01$ & 10 & 0 & $<0.01$ \\
\hline 3 & 4.75 & 2.29 & $<0.01$ & 35.4 & 3.6 & 0.02 \\
\hline
\end{tabular}

${ }^{\mathrm{w}}$ The following rating system was used: $0=$ no sclerotia; $1=1$ to 25 sclerotia; $2=26$ to 50 sclerotia; $3=51$ to 100 sclerotia; $4=101$ to 250 sclerotia; $5=251$ to 500 sclerotia; $6=501$ to 1,000 sclerotia; $7=>1,000$ sclerotia present.

${ }^{x}$ Percentage of seed within inoculated locules in which sclerotia were observed during bisection and observation under a dissecting microscope (30X).

y Values for tests 1 and 2 are means of four replicates; each replicate is the mean for all bolls inoculated with one of four S strain isolates. Different $\mathrm{S}$ strain isolates were used in tests 1 and 2 . Values for test 3 are means of either seven ( $>30$ days old) or 16 ( $<30$ days old) replicates in which each replicate is the value from a single locule inoculated with LA2-5. In all tests, one locule per boll was inoculated.

${ }^{z}$ Statistical significance of differences between bolls < 31 days old and bolls $>30$ days old at inoculation.

TABLE 4. Influence of Aspergillus flavus isolate AF36 on aflatoxin contamination of developing cottonseed by aflatoxin producing isolates of $A$. flavus $\mathrm{L}$ strain and S strain

\begin{tabular}{lcccc}
\hline & & \multicolumn{2}{c}{ Aflatoxin $\mathrm{B}_{1}(\mu \mathrm{g} / \mathrm{kg})$} & \\
Isolate & Strain & Alone & Coinoculated & Reduction $(\%)$ \\
\hline Test 1 & & & & \\
D2-18 & $\mathrm{L}$ & $52,831^{\mathrm{y}}$ & 6,213 & $88.34^{\mathrm{z}}$ \\
PM11 & $\mathrm{L}$ & 101,632 & 3,832 & 96.23 \\
12 & $\mathrm{~S}$ & 177,186 & 100 & 99.94 \\
65 & $\mathrm{~S}$ & 386,788 & 19 & 99.99 \\
Test 2 & & & & \\
WHT-3 & $\mathrm{L}$ & 1,488 & 4,024 & $\mathrm{NS}$ \\
YV1 & $\mathrm{L}$ & 531 & 0 & $\mathrm{NS}$ \\
D2-X & $\mathrm{S}$ & 91,046 & 14 & 99.99 \\
PM3 & $\mathrm{S}$ & 108,640 & 45 & 99.96 \\
\hline
\end{tabular}

y Values listed are means of five replicates.

${ }^{z}$ Percent reductions are significant $(P=0.01)$ by Fisher's protected least significant difference test except where indicated NS (not significant). 
current study, it seems likely that Waked and Nouman (27) were observing contamination caused by the $\mathrm{S}$ strain. Sclerotia may be important for overwintering (11) and, as such, formation of sclerotia in developing seed and on locule surfaces may provide an important survival benefit. The $\mathrm{S}$ strain, which produces fewer conidia than the L strain (4), may also rely on sclerotia for dispersal. Formation of sclerotia within seed may permit dispersal by herbivorous rodents and birds; formation of sclerotia on locule surfaces is ideal for scattering by modern spindle pickers. Indeed, through dispersal of sclerotia during spindle picking, cotton production may facilitate success of $\mathrm{S}$ strain isolates.

Production of sclerotia in developing seed and on locule surfaces varied with boll age at inoculation. Previous studies showed boll age also influences aflatoxin contamination (5). Optimal boll ages at inoculation for both aflatoxin and sclerotial formation are similar, 21 to 32 days after anthesis. Regulation of sclerotial morphogenesis and aflatoxin biosynthesis are interrelated (3) and, thus, it is not surprising that the two coincide. Simultaneous formation of both aflatoxins and sclerotia within cottonseed by A. flavus may have both ecological and toxicological significance. Impregnating tissues surrounding sclerotia with aflatoxins may serve to protect sclerotia from insect predation and to prevent utilization of nutritional resources in the seed by competitors (11). Production of sclerotia in the seed may also increase seed toxicity. In addition to aflatoxins, several other highly toxic compounds are known to be concentrated within sclerotia of A. flavus $(28,29)$, and synergism in toxicity is known between at least one of these compounds and aflatoxin (14). Furthermore, accumulation of tremorgenic indoloterpenes and other toxic compounds specifically within S strain sclerotia has been described (17). It, therefore, seems likely that $S$ strain sclerotia within commodities cause levels of toxicity beyond that caused by the aflatoxin content alone. Infections by $\mathrm{S}$ strain isolates may, thus, cause an unrealized decrease in commodity safety, a decrease not associated with many $\mathrm{L}$ strain isolates.

Atoxigenic L strain isolate AF36 performed as previously described $(6,10)$, by significantly reducing ( 88 to $99 \%$ ) the aflatoxin $\mathrm{B}_{1}$ content of bolls inoculated with six of the eight isolates evaluated. Isolate AF36 also significantly reduced the number of sclerotia formed on locule surfaces and, in some cases, the percentage of seed containing sclerotia. Failure of AF36 to significantly reduce either aflatoxin contamination or sclerotial formation in some treatments probably reflects the great variability in aflatoxin and sclerotial production and not lack of an influence by AF36. AF36 apparently reduced both contamination and sclerotial formation through competitive exclusion as previously described (10). This conclusion is supported by formation of equal quantities of conidiophores and conidia within seed inoculated with AF36 either alone or in combination with an S strain isolate, but failure of conidiophores to form in seed inoculated with $S$ strain isolates alone.

In no case did coinoculation with AF36 increase loss of locule weight over losses associated with inoculation of S strain isolates alone. Apparently, A. flavus AF36 does not have increased boll rot ability compared with the tested $\mathrm{S}$ strain isolates. Thus, ability to competitively exclude aflatoxin-producing isolates is not necessarily associated with increased boll rot ability. Indeed, AF36 had less boll rot ability than two S strain isolates (YV1-1 and PM 3) (Table 1) that it was effective at excluding.

There is interest in developing A. flavus AF36 as a biological control agent that can increase cottonseed safety by decreasing the aflatoxin content $(7,8)$. The ability of isolate AF36 to inhibit sclerotial formation in developing cottonseed by highly aflatoxigenic isolates of the $S$ strain may serve to reduce overwintering of $S$ strain isolates and increase the long-term impact of AF36 on the aflatoxin-producing potential of fungal populations. Decreasing the incidence of sclerotia within infected cottonseed is a second mechanism by which AF36 may cause improved commodity safety.

\section{ACKNOWLEDGMENTS}

We thank D. L. Downey for technical assistance and B. Vinyard for statistical assistance.

\section{LITERATURE CITED}

1. Bayman, P., and Cotty, P. J. 1991. Vegetative compatibility and genetic diversity in the Aspergillus flavus population of a single field. Can. J. Bot. 69:1707-1711.

2. Bayman, P., and Cotty, P. J. 1993. Genetic diversity in Aspergillus flavus: Association with aflatoxin production and morphology. Can. J. Bot. 71:23-31.

3. Cotty, P. J. 1988. Aflatoxin and sclerotial production by Aspergillus flavus: Influence of $\mathrm{pH}$. Phytopathology 78:1250-1253.

4. Cotty, P. J. 1989. Virulence and cultural characteristics of two Aspergillus flavus strains pathogenic on cotton. Phytopathology 79:808-814.

5. Cotty, P. J. 1989. Effects of cultivar and boll age on aflatoxin in cottonseed after inoculation with Aspergillus flavus at simulated exit holes of the pink bollworm. Plant Dis. 73:489-492.

6. Cotty, P. J. 1990. Effect of atoxigenic strains of Aspergillus flavus on aflatoxin contamination of developing cottonseed. Plant Dis. 74:233-235.

7. Cotty, P. J. 1992. Use of native Aspergillus flavus strains to prevent aflatoxin contamination. U.S. patent 5,171,686.

8. Cotty, P. J. 1994. Influence of field application of an atoxigenic strain of Aspergillus flavus on the populations of A. flavus infecting cotton bolls and on aflatoxin content of cottonseed. Phytopathology 84:1270-1277.

9. Cotty, P. J. Aflatoxin-producing potential of communities of Aspergillus section Flavi from cotton producing areas in the United States. Mycol. Res. In press.

10. Cotty, P. J., and Bayman, P. 1993. Competitive exclusion of a toxigenic strain of Aspergillus flavus by an atoxigenic strain. Phytopathology 83: 1283-1287.

11. Cotty, P. J., Bayman, P., Egel, D. S., and Elias, K. S. 1994. Agriculture, aflatoxins, and Aspergillus. Pages 1-27 in: The Genus Aspergillus: From Taxonomy and Genetics to Industrial Applications. K. A. Powell, A. Renwick, and J. F. Peberdy, eds. Plenum Press, New York.

12. Cotty, P. J., and Lee, L. S. 1989. Aflatoxin contamination of cottonseed: Comparison of pink bollworm damaged and undamaged bolls. Trop. Sci. 29:273-277.

13. Doster, M. A., and Michailides, T. J. 1994. Development of Aspergillus molds in litter from pistachio trees. Plant Dis. 78:393-397.

14. Dowd, P. F. 1988. Synergism of aflatoxin $B_{1}$ toxicity with the co-occuring fungal metabolite kojic acid to two caterpillars. Entomol. Exp. Appl. 47:69-71.

15. Emnett, J. 1989. Aflatoxin contamination problems in milk caused by cottonseed products. Feedstuffs 61:1-22.

16. Horne, B. W., Dorner, J. W., Greene, R. L., Blankenship, P. D., and Cole, R. J. 1994. Effect of Aspergillus parasiticus soil inoculum on invasion of peanut seeds. Mycopathologia 125:179-191.

17. Nozawa, K., Sekita, S., Harada, M., Udagawa, S., and Kawai, K. 1989. Isolation and structures of two new indoloterpenes related to aflavine from a microsclerotium-producing strain of Aspergillus flavus. Chem. Pharm. Bull. (Tokyo) 37:626-630.

18. Orum, T. V., Bigelow, D. M., Nelson, M. R., Howell, D. R., and Cotty, P. J. Spatial and temporal patterns of Aspergillus flavus strain composition and propagule density in Yuma County, AZ, soils. Plant Dis. In press.

19. Park, D. L., Lee, L. S., Price, R. L., and Pohland, A. E. 1988. Review of the decontamination of aflatoxins by ammoniation: Current status and regulation. J. Assoc. Off. Anal. Chem. 71:685-703.

20. Park, D. L., and Stoloff, L. 1989. Aflatoxin control-How a regulatory agency managed risk from an unavoidable natural toxicant in food and feed. Regul. Toxicol. Pharmacol. 9:109-130.

21. Pons, W. A., Jr., Robertson, J. A., and Goldblatt, L. A. 1966. Collaborative study on the determination of aflatoxins in cottonseed products. J. Am. Oil Chem. Soc. 43:655-669.

22. Robens, J. F., and Richard, J. L. 1992. Aflatoxins in animal and human health. Rev. Environ. Contam. Toxicol. 127:69-94.

23. Samson, R. S., and Frisvad, J. C. 1990. Taxonomic species concepts of hyphomycetes related to mycotoxin production. Proc. Jpn. Assoc. Mycotoxicol. 32:3-10.

24. Shearer, J. F., Sweets, L. E., Baker, N. K., and Tiffany, L. H. 1992. A study of Aspergillus flavus/parasiticus in Iowa crop fields: 1988-1990. Plant Dis. 76:19-22.

25. Sokal, R. R., and Rohlf, F. J. 1981. Biometry. W. H. Freeman \& Co., San Francisco.

26. Stoloff, L., van Egmond, H. P., and Park, D. L. 1991. Rationales for the 
establishment of limits and regulations for mycotoxins. Food Addit. Contam. 8:213-222.

27. Waked, M. Y., and Nouman, K. A. 1982. The relationship of sclerotia formation to aflatoxin content of cottonseeds infected with Aspergillus flavus Link. Med. Fac. Landbouww. Rijksuniv. Gent. 47: 201-209.

28. Wicklow, D. T., and Cole, R. J. 1982. Tremorgenic indole metabolites and aflatoxins in sclerotia of Aspergillus flavus: An evolutionary per- spective. Can. J. Bot. 60:525-528

29. Wicklow, D. T., Dowd, P. F., and Gloer, J. B. 1994. Antiinsectan effects of Aspergillus metabolites. Pages 93-114 in: The Genus Aspergillus: From Taxonomy and Genetics to Industrial Applications. K. A. Powell, A. Renwick, and J. F. Peberdy, eds. Plenum Press, New York.

30. Wicklow, D. T., and Horn, B. W. 1984. Aspergillus flavus sclerotia form in wound-inoculated preharvest corn. Mycologia 76:503-505. 